\title{
Application to the Motion and Equilibrium of the Planar Kinematic Chains with Rotational Links with Clearances
}

\author{
Jan-Cristian Grigore ${ }^{1}$, Alexandru Jderu ${ }^{2}$, Marius Enachescu ${ }^{2 *}$ \\ ${ }^{1}$ University of Piteşti, Piteşti, 110040, Romania \\ ${ }^{2}$ University POLITEHNICA of Bucharest, Bucharest, 060042, Romania \\ * Corresponding author: marius.enachescu@upb.ro
}

Abstract: Based on the algorithm presented in our previous papers [1], we now present their applications to a few problems.

\section{Application}

We consider the planar kinematical chain from the Figure 1

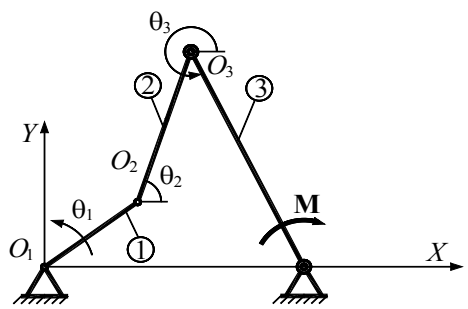

Figure 1. Quadrilateral mechanism with clearances in the kinematical joints $\mathrm{O}_{3}, \mathrm{O}_{4}$.

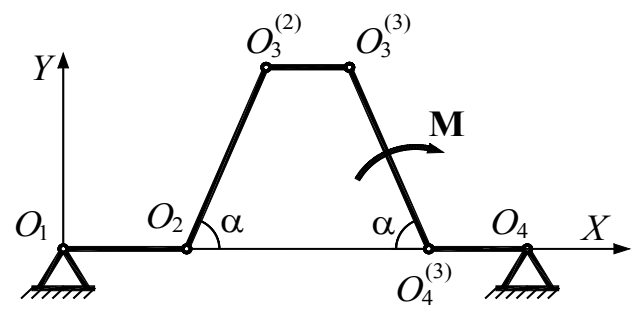

Figure 2.. Initial position of the quadrilateral mechanism with clearances.

Determine the equations of motion and the reactions for the mechanism
$\mathrm{O}_{1} \mathrm{O}_{2} \mathrm{O}_{3} \mathrm{O}_{4}$ with clearances in the rotational kinematical joints $\mathrm{O}_{3}, \mathrm{O}_{4}$, Figure 1, knowing that the element $\mathrm{O}_{1} \mathrm{O}_{2}$ rotates with constant angular speed $\omega$ and the element $\mathrm{O}_{3} \mathrm{O}_{4}$ is acted by a torque with the moment $M$. We consider that the elements of the mechanism are homogeneous bar of constant cross section and we consider known the following parameters:

- dimensions $l_{1}=O_{1} O_{2}, l_{2}=O_{2} O_{3}$, $l_{3}=O_{3} O_{4}, l_{1}=l_{2}$;

- the coordinates $X_{O_{4}}, Y_{O_{4}}=0$ of the articulation $\mathrm{O}_{4}$;

- the clearances $r_{3}, r_{4}$ at the joints $\mathrm{O}_{3}$, $\mathrm{O}_{4}$;

- the masses $m_{3}, m_{4}$ and the moments of inertia $J_{2}, J_{3}$;

- the initial conditions, Figure. 2, at $t=0$ : $X_{O_{4}}=l_{1}+2 l_{2} \cos \alpha+r_{3}+r_{4}, \theta_{2}=\alpha$, $X_{2}=l_{1}+\frac{l_{2}}{2} \cos \alpha, \quad Y_{2}=\frac{l_{2}}{2} \sin \alpha$, $\theta_{3}=-\alpha, X_{3}=X_{O_{4}}-r_{4}-\frac{l_{2}}{2} \cos \alpha$, 


$$
\begin{aligned}
& \dot{X}_{2}=0, \quad \dot{Y}_{2}=l_{1} \omega, \quad \dot{\theta}_{2}=0, \\
& \dot{X}_{3}=\dot{Y}_{3}=0, \dot{\theta}_{3}=0 . \\
& \quad \text { Numerical } \quad \text { application } \quad \text { for } \\
& l_{1}=0.2 \mathrm{~m}, \quad l_{2}=l_{3}=0.6 \mathrm{~m}, \\
& r_{3}=r_{4}=0.005 \mathrm{~m}, m_{2}=m_{3}=2 \mathrm{~kg}, \\
& J_{2}=J_{3}=0.06 \mathrm{kgm}^{2}, M=40 \mathrm{Nm}, \\
& \omega=10 \mathrm{rad} / \mathrm{s} .
\end{aligned}
$$

Solution: Based on the previous relations of calculation, we can write in order the equalities $\widetilde{x}_{2}^{(2)}=-\frac{l_{2}}{2}, \widetilde{y}_{2}^{(2)}=0$, $\widetilde{U}_{2 X}=\tilde{x}_{2}^{(2)} \cos \theta_{2}, \widetilde{U}_{2 Y}=\tilde{x}_{2}^{(2)} \sin \theta_{2}$, $\left[\widetilde{\mathbf{B}}_{2}^{(2)}\right]=\left[\begin{array}{ccc}1 & 0 & -\widetilde{U}_{2 Y} \\ 0 & 1 & \widetilde{U}_{2 X}\end{array}\right], \quad x_{3}^{(2)}=\frac{l_{2}}{2}$, $y_{3}^{(2)}=0 \quad, \quad U_{3 X}^{(2)}=x_{3}^{(2)} \cos \theta_{2}$ $U_{3 Y}^{(2)}=x_{3}^{(2)} \sin \theta_{2} \quad, \quad x_{3}^{(3)}=-\frac{l_{2}}{2}$, $y_{3}^{(3)}=0 \quad, \quad U_{3 X}^{(3)}=x_{3}^{(3)} \cos \theta_{3}$ $U_{3 Y}^{(3)}=x_{3}^{(3)} \sin \theta_{3}$

$D_{3 X}=\frac{X_{3}+U_{3 X}^{(3)}-X_{2}-U_{3 X}^{(2)}}{r_{3}}$

$D_{3 Y}=\frac{Y_{3}+U_{3 Y}^{(3)}-Y_{2}-U_{3 Y}^{(2)}}{r_{3}}$

$\left\{\mathbf{D}_{3}\right\}=\left[\begin{array}{c}D_{3 X} \\ D_{3 Y}\end{array}\right],\left[\mathbf{B}_{3}^{(2)}\right]=\left[\begin{array}{ccc}1 & 0 & -U_{3 Y}^{(2)} \\ 0 & 1 & U_{3 X}^{(2)}\end{array}\right]$, $\left[\mathbf{B}_{3}^{(3)}\right]=\left[\begin{array}{ccc}1 & 0 & -U_{3 Y}^{(3)} \\ 0 & 1 & U_{3 X}^{(3)}\end{array}\right]$

$\left[\mathbf{E}_{3}^{(2)}\right]=\left\{\mathbf{D}_{3}\right\}^{T}\left[\mathbf{B}_{3}^{(2)}\right],\left[\mathbf{E}_{3}^{(3)}\right]=\left\{\mathbf{D}_{3}\right\}^{T}\left[\mathbf{B}_{3}^{(3)}\right]$, $x_{4}^{(3)}=\frac{l_{3}}{2}, y_{4}^{(3)}=0, U_{4 X}^{(3)}=x_{4}^{(3)} \cos \theta_{3}$, $U_{4 Y}^{(3)}=x_{4}^{(3)} \sin \theta_{3}, x_{4}^{(3)}=\frac{l_{3}}{2}, y_{4}^{(3)}=0$, $U_{4 X}^{(3)}=x_{4}^{(3)} \cos \theta_{3}, U_{4 Y}^{(3)}=x_{4}^{(3)} \sin \theta_{3}$,
$\left[\mathbf{B}_{4}^{(3)}\right]=\left[\begin{array}{ccc}1 & 0 & -U_{4 Y}^{(3)} \\ 0 & 1 & U_{4 X}^{(3)}\end{array}\right]$

$D_{4 X}=\frac{X_{O_{4}}-X_{3}-U_{4 X}^{(3)}}{r_{4}}$

$D_{4 Y}=\frac{Y_{O_{4}}-Y_{3}-U_{4 Y}^{(3)}}{r_{4}},\left\{\mathbf{D}_{4}\right\}=\left[\begin{array}{c}D_{4 X} \\ D_{4 Y}\end{array}\right]$, $\left[\mathbf{E}_{4}^{(3)}\right]=\left\{\mathbf{D}_{4}\right\}^{T}\left[\mathbf{B}_{4}^{(3)}\right]$

$[\mathbf{B}]=\left[\begin{array}{cc}{\left[\mathbf{B}_{2}^{(2)}\right]} & {[\mathbf{0}]} \\ -\left[\mathbf{E}_{3}^{(2)}\right] & {\left[\mathbf{E}_{3}^{(3)}\right]} \\ {[\mathbf{0}]} & -\left[\mathbf{E}_{4}^{(3)}\right]\end{array}\right]$

$\{\mathbf{C}\}=l_{1} \omega\left[\begin{array}{llll}-\sin \omega t \cos \omega t & 0 & 0\end{array}\right]^{T}$

$\{\mathbf{q}\}=\left[\begin{array}{llllll}X_{2} & Y_{2} & \theta_{2} & X_{3} & Y_{3} & \theta_{3}\end{array}\right]^{T}$

$\{\mathbf{R}\}=\left[\begin{array}{llll}H_{2} & V_{2} & N_{3} & N_{4}\end{array}\right]^{T}$

$\left[\begin{array}{llllll}m_{2} & 0 & 0 & 0 & 0 & 0\end{array}\right]$ $\begin{array}{llllll}0 & m_{2} & 0 & 0 & 0 & 0\end{array}$

$[\mathbf{M}]=\left[\begin{array}{cccccc}0 & 0 & J_{2} & 0 & 0 & 0 \\ 0 & 0 & 0 & m_{3} & 0 & 0 \\ 0 & 0 & 0 & 0 & m_{3} & 0 \\ 0 & 0 & 0 & 0 & 0 & J_{3}\end{array}\right]$ and, since the matrix $[\mathbf{M}]$ is invertible, it results that the equation $[\mathbf{M}]\{\ddot{\mathbf{q}}\}=\{\mathbf{F}\}-[\mathbf{B}]^{T}\{\mathbf{R}\}$ separates into the equalities

$$
\begin{aligned}
& \{\mathbf{R}\}=\left[[\mathbf{B}][\mathbf{M}]^{-1}[\mathbf{B}]^{T}\right]^{-1}\left\{[\mathbf{B}][\mathbf{M}]^{-1}\{\mathbf{F}\}-\{\dot{\mathbf{C}}\}+[\dot{\mathbf{B}}]\{\dot{\mathbf{q}}\}\right\} \\
& \{\ddot{\mathbf{q}}\}=[\mathbf{M}]^{-1}\left\{\{\mathbf{F}\}-[\mathbf{B}]^{T}\{\mathbf{R}\}\right\} .
\end{aligned}
$$

Further on, with the aid of the notations $\{\mathbf{f}\}=\left[\begin{array}{llll}f_{1} & f_{2} & \ldots & f_{6}\end{array}\right]^{T}=[\mathbf{M}]^{-1}\left\{\{\mathbf{F}\}-[\mathbf{B}]^{T}\{\mathbf{R}\}\right\}$ ,$p_{i}=\left\{\begin{array}{c}q_{i}, \text { if } 1 \leq i \leq 6 \\ \dot{q}_{i}, \text { if } 7 \leq i \leq 12\end{array}\right.$, one obtains from (1) the systems of first order differential equations $\quad \frac{\mathrm{d} p_{i}}{\mathrm{~d} t}=\left\{\begin{array}{c}q_{i}, \text { if } 1 \leq i \leq 6 \\ \dot{q}_{i}, \text { if } 7 \leq i \leq 12\end{array}\right.$ which, by numerical integration using the 
fourth order Runge-Kutta, leads us to the results captured in Figures. 3-12

From the Figure 3 we observe that the variations of the kinematical parameters $\mathrm{O}_{2}, \mathrm{O}_{3}$ in the case with clearance are small relative to the case without clearance. These variations diminish when the clearances $r_{3}$,

$r_{4}$ diminish.

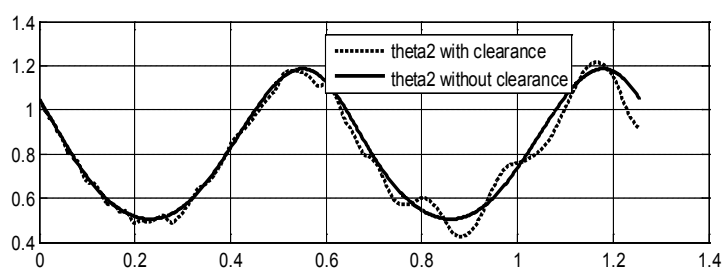

Figure 3. Time history of the parameters $q_{2}$ in the cases without and with clearances.

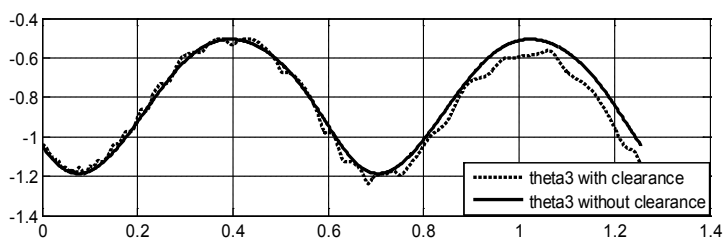

Figure 4. Time history of the parameters $q_{3}$ in the cases without and with clearances.

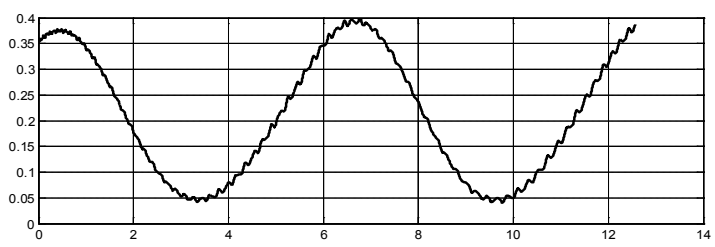

Figure5. Time history of the parameter $X_{2}$.

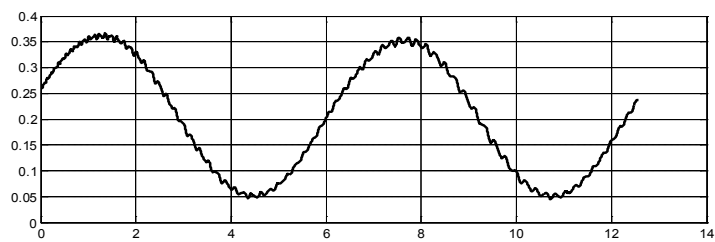

Figure 6. Time history of the parameter $Y_{2}$.

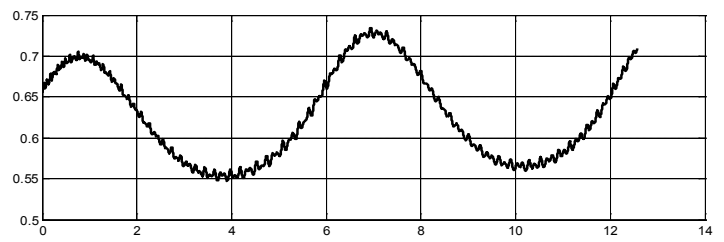

Figure 7. Time history of the parameter $X_{3}$.

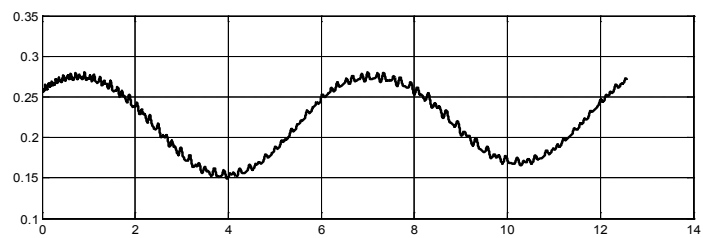

Figure 8. Time history of the parameter $Y_{3}$.

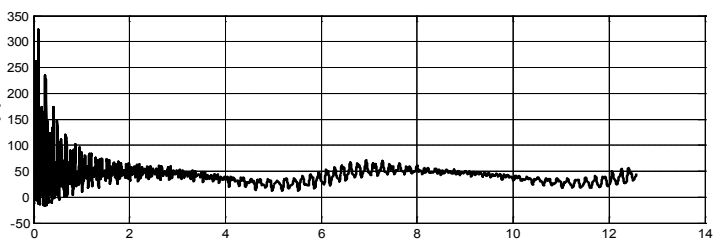

Figure 9. Time history of the reaction $\mathrm{H}_{2}$.

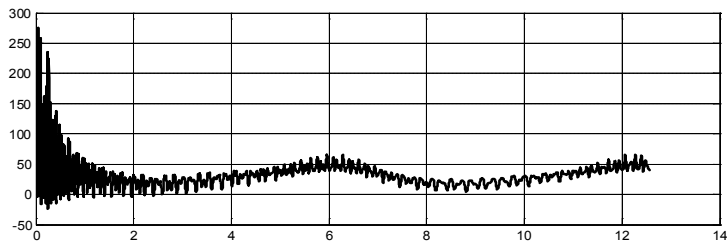

Figure 10. Time history of the reaction $V_{2}$.

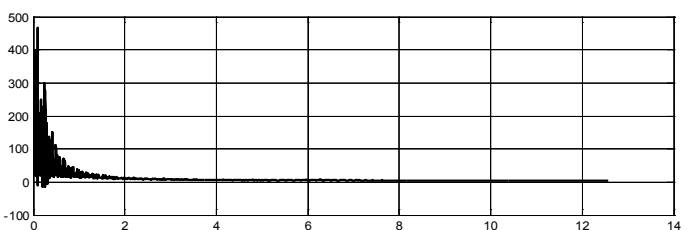

Figure 11. Time history of the reaction $N_{3}$.

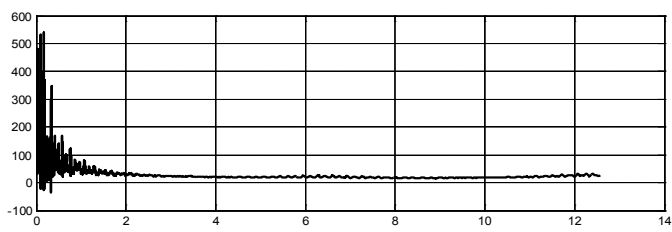

Figure 12. Time variation of the reaction $N_{4}$. 


\section{Conclusions}

In this paper we presented one application concerning the motion and the equilibrium of the planar chains with rotational linkages with clearances. The applications are complete and numerically solved.

The numerical applications solved here confirm the statements mentioned on the algorithm presented in our previous papers.

\section{Acknowledgement}

This work was supported by Romanian Ministry of Education and by Executive Agency for Higher Education, Research, Development and Innovation Funding, under projects PCCA 2-nr. 166/2012 and ENIAC 04/2014.

\section{References}

1) Grigore, J.-C, Jderu A., Enachescu M., Matrix of Constraints for the Motion of the Planar Kinematic Chains with Rotational Links with Clearances, The 39th ARA, 28 - 31 July 2015, Franscati, Rome, Italy, Proceedings American Romanian Academy of Arts and Sciences ISBN: 978-1-935924-18.

2) Amirouche, F., Fundamentals of multibody dynamics. , Birkhänser, Boston, Berlin, (2004).

3) Constantinescu, G., Teoria sonicității, Editura Academiei R.S.R, București, (1985).

4) Erkaya, S., Uzmay, I., Investigation on effect of joint clearance on dynamics of four-bar mechanism. Nonlinear Dyn., 58, 179-198, (2009).

5) Flores, P., Ambrósio, J., Revolute joints with clearance in multibody systems. Comput. Struct. 82, 1359-1369, (2004).

6) Flores, P., Modeling and simulation of wear in revolute clearance joints in multibody systems. Mechanism and
Machine Theory, 44, 1211-1222, (2009).

7) Grigore, J.-C., Contribution to the dynamical study of the mechanisms with clearances. Doctoral thesis, University of Piteşti, (2008).

8) Pandrea, N., The dynamic calculation of mechanical torque converter , G. Constantinescu " IFToMM Int. Symp. SYROM 89 pag. 673-679, Bucharest, Romania,(1989).

9) Pandrea, N., Popa, D., Mechanisms. Technical Publishing, Bucharest, (2000).

10) Penestri, E., Valentini, P., P., Vito, L., Multibody dynamics simulation of planar linkages with Dahl friction, Multibody Syst. Dyn. 17, 321-347, (2007).

11) Pfeiffer, F., Glocker, C., Multibody dynamics with unilateral contacts. Wiley, New York (1996).

12) Ravn, P., A continuous analysis method for planar multibody systems with joint clearance. Multibody Syst. Dyn. 2, 124, (1998).

13) Samanta, B., Mukherjee, A., Deb, K., Bond graph adaptive modular approach to analysis of planar mechanisms, World Congress Mechanisms and Machine Theory, vol. III, pag. 439-443, Sevilla, Spain, (1987).

14) ShabanA A., A., Dynamics of multibody systems. Cambridge University Press, Cambridge, 2005

15) Stoenescu, E., D., Marghitu, D.B., Dynamic analysis of a planar rigid-link mechanism with rotating slider joint and clearance, J. Sound Vib. 266, 394404, (2003). 